\title{
Analysis between the location of pharmacies and urban planning in Quitilipi, Chaco from the new economic geography
}

\begin{abstract}
Background: A descriptive and empirical research process that is based on a state of the art that began its construction with the contributions of Richard Cantillon and Adam Smith in the middle of the 18th century and which is still being built thanks to the contributions of a large number of scholars and professionals around the world. Among them, it is worth highlighting the Nobel Prize in Economics, awarded in 2008 in addition, awarded the John Bates medal in 1991 and the Prince of Asturias Prize for Social Sciences in 2004, Paul Krugman also for his work on international trade that he led to the design of a "New Economic Geography" (NGE) and a "New Trade Theory", aspects that acquire great relevance as far as my research is concerned. Also the Japanese economist and urban planner, the co-founder of space economics and pioneer of the NGE outstanding in research fields on urban economics and regional economics.

The search for successive chronological information based on the years was the tool used, achieving real data on the geographical location, number of pharmacies and the urban dynamism of the city. In addition, a database was created with the intention of extrapolating results to extract consequences by verifying hypotheses; as well as the implementation of similar studies in other locations. The dynamic construction of the new geography establishes existing parallels between urban development and the location of new commercial ventures, which makes up the significant contribution, which allows this thesis to contribute a grain of sand in the construction of a state of the art and full knowledge process of continuous and endless evolution. Sectors that will be able to use this tool in order to optimize their own needs: urban planning, commercial undertakings, construction and real estate.
\end{abstract}

Keywords: new economic geography, location, new commercial area
Volume 9 Issue 3 - 202 I

\section{Gerardo Ariel Saez}

Department of Pharmacy, Chaco Austral National University, Argentina

Correspondence: Gerardo Ariel Saez, Farmacia, Chaco Austra National University, Roque Saenz Peña Chaco Presidency, Argentina, Tel +5493644420 I37, Email gas@uncaus.edu.ar

Received: March 3I, 202I | Published: May 25, 202 I

\section{Introduction}

A analysis of descriptive and explanatory nature of the determinants of the distribution of pharmaceutical offices in the town of Quitilipi, Chaco. The interest in knowing the constitutive elements of this geographical distribution is specifically focused on the study of the incidence of New Economic Geography (NGE) in elucidating it. It is necessary to have the four legs of a table, after this statement, we proceed to assign them (making the corresponding analogy) the first would be the city, the second the economic activity, the third NGE and the last would be the analysis itself. From the beginning of the formation of urban society and the concentration of people in nearby inhabited environments to achieve common interests, commerce appears directly linked to the center of the city. For this reason, they are not two different things but parts of a whole and it would be very difficult to define the city center from any point of view, be it economic, urban, environmental or social, without using the word commerce. ${ }^{1}$

The central area manifests as a common factor the concentration of the main shops and other entities of importance for the development of the social life of the inhabitants, presenting an oversaturation in the commercial offer and decreasing (decreasing until exhaustion when moving away from it). From the perspective of economic activity growth, the increase in the central commercial area of a city is considered a positive factor of progress that favors all sectors of the city since commerce is recognized as a dynamic agent of social life and urban. ${ }^{2}$ However, at some point, growth is favorable in peripheral urban areas where success is potentially considerable, the evolution of which cannot be explained only by demographic evolution but also by other factors. ${ }^{3}$

At some point, the synergism manifested between shops and the center begins to be detrimental and makes it impossible to install new offers and in particular to install new Small and Medium Enterprises (SMEs), including pharmacy offices, considering the central location as an essential factor. Decentralization constitutes an indispensable tool in this process, because it grants competences, resources and responsibilities to the different territorial instances. ${ }^{4}$

In addition, the saturation of commercial establishments in the most favorable locations makes it difficult to make decisions regarding future locations of new SMEs such as pharmacy offices in the city center; periphery and shopping centers, motivating the investigation of constituent factors that allow unravel future alternatives.

\section{Methods}

The methodology to be used will be a descriptive, retrospective study (from 2015 to 1912) and explanatory on the location of all the pharmacy offices in the city of Quitilipi and their relationship with the urban development of this city from its foundation to the present. This will allow an exhaustive analysis of the possible application of the 
NGE macroeconomic theory in the city of Quitilipi. L as NGE applied to industries where the concentration of economic activities can be viewed as the result of the snowball effect, specifically, more and more agents want to agglomerate because the various factors that allow greater diversity and greater specialization in production processes, leading to a wider range of products available for consumption. The city in its origin as well as the first pharmacies and the way in which the city affects their distribution. In addition, the description of the characteristics that identify the different elements and components of the city and their interrelation will be carried out; establishing the demographic characteristics of the investigated units (population number, age distribution, education level, etc.). Explanatory: it will indicate what are the main causes and effects of the influence of urban development in a positive or negative way in the advancement of pharmacy offices through the study of the variables involved in it, establishing the historical relationship between cause-effect.

\section{Results}

Urban growth occurs initially at the edges, where the value of the land is minimal, forming growth rings. However, each new ring adds centrality to all other pre-existing rings, particularly the most central ones, where the difference between actual and expected income grows enough to become unstable buildings; possibly, the decision to destroy an existing building and replace it with another, compatible with the expected income is made..$^{5-13}$

Analysis from 1) mass production (economies of scale), 2) the formation of a highly specialized workforce and the production of new ideas, both based on the accumulation of human capital and faceto-face communications, 3) availability specialized input services, and 4) the existence of modern infrastructures. Its effects result from relating technological and pecuniary externalities; As a consequence, each type of externality can give rise to the spatial agglomeration of the economy. ${ }^{14}$ In this way, the exchange of one building for another suggests the occurrence of a critical point in the evolution of that place, whose change in state or phase of stabilization, even that location affects the stability of many others, can cause more or less extensive changes and deep in urban morphology. ${ }^{15}$
The classical imaginary by Bak uses to describe systems that type is the pile of sand formed by the addition of successive grains from the same point arranged on top of a flat surface. As the grains accumulate on this surface, a large quantity takes shape; the slope of the slope tends to increase to a point where a new grain finds no support and an avalanche is formed. According to Bak, the time and magnitude of avalanches cannot be predicted, but the frequency of the type of occurrence can be described by a power law that is calculated. ${ }^{16}$

Changes in building density are, evidently, followed by the use of these that determine variations in population density, equivalent to more frequent users of a certain eventual service or, in the same way that they are implied by changing socioeconomic patterns in residents, the cycle of changes in social customs they are getting shorter and shorter. This process will not present a balance as long as it maintains a growth pattern in the city, that is, growth and structural variations. ${ }^{17,18}$

1. North Pharmacy. Intersection Mendoza and Santa Fe

2. Nueva Belgrano Pharmacy. San Martin 540

3. Markonich Pharmacy . Tucuman 570

4. Urlich Pharmacy . San Juan 560

5. Quitilipi Pharmacy. San Martin 580

6. Itatí Pharmacy. Intersection Av. 25 de mayo and Entre Ríos

7. New Millennium Pharmacy. San Martin 690

8. Vital Pharmacy. Cordoba 765

9. INSSSEP Pharmacy. Intersection Av. Chaco and Buenos Aires

10. Pharmacy Employee Center of Commerce. Santa Fe 810

11. Avenida Pharmacy. Av. 25 de Mayo 790

12. Santa Rita Pharmacy. Av. 25 de Mayo 770

13. Diaz Pharmacy. Admiral Brown Access 550

14. San Antonio Pharmacy. Santa Cruz 740

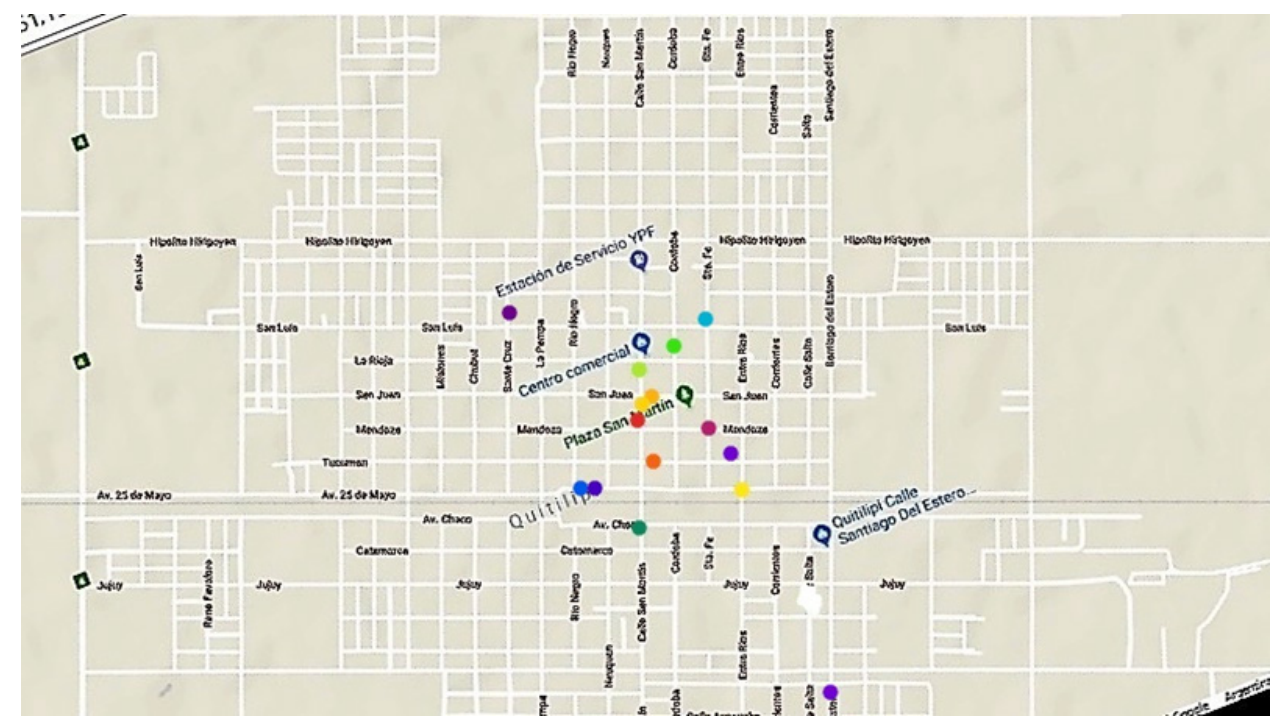

E 1 epicenter of the nascent societies phenomenon is repeated throughout the territory. The railways reported to Chaco the virtual foundation of around 60 settlements that today are counted as key cities of regional progress, among them Presidencia Roque Sáenz
Peña, Quitilipi, etc. The railroad gravitated as a factor in colonization, without a doubt, it was the starting point. From these beginnings, described as a hamlet next to the road (station), it was modified by moving, mutating, adapting, adapting to the new self-generated 
demands; both for the mosaic of the city as well as for the mobility of people from the southern sector to the north, considering the roads themselves as a meridian.

The place chosen by immigrants for decades: everything had to be done, the land promised a lot, the finding of soils suitable for farming and grazing and the thick mountains with good wood were reason enough to settle and face the arduous but promising task of converting it in a future agricultural space. The entities, the businesses, the new family houses and the rest of the development progressed in this sense, with this; it coincides with the place of settlement of the pharmacies. First around the railway but always on the north side. The great changes take place with the asphalt, the first asphalt urban streets definitively specify the downtown area giving a definite shape to the urbanization of the city; with its own logical self-generation, as well as modification.

Later staying in the vicinity of health hospitals or in the development of the main institutions, mail police, church, municipality civil registry, etc. Firstly, medical and polyclinics offices and (private) hospitals and (public) hospitals later are alterations in the geography of the city that in turn, always accompanied by demographic growth; determine the factors of the emergence of new ventures, subject of study. This is where the installation of the Norte, Belgrano and Markonich pharmacies stands out.

Over the years, new and different businesses emerge, including morphological changes in the city that define a dissimilar event on the main street. Visually objectively foreseeable modifications alterations in the economic geography that in turn allows the emergence of new strategic places for SMEs. Here are Urlich, Quitilipi, Itatí, Nuevo Milenio and Vital pharmacies. It is worth mentioning that there were very few new paved streets, if the city was expanded towards the cardinal points. Acceptable analysis until the areas with greater urban economic importance diminish due to their own importance, this does not imply the decline of the commercial system but the possibility of expansion or breaking into commercial areas other than the central one. Where polycentric systems could occur or simply areas of the periphery take importance, which determines the existence with their respective location of the INSSSEP Pharmacies, Quitilipi Commercial Employees Center, Avenida, Santa Rita, Díaz and San Antonio. In this period, the new asphalt streets and the area of influence coincide with the new pharmacies.

\section{Discussion}

The central region can have localization disadvantages. Strong competition between companies reduces profits in the central region. As a result, companies can leave the central region of the peripheries in order to avoid competition and seek a small, reduced but also exclusive market, causing this situation from the proximity of supply to demand. This shows the relevance of economic geography for MSMEs since new cities imply new opportunities and the growth of cities, the growth of opportunities.

Jointly, the compatibility of changes inherent to progress and variations in the socioeconomic behavior patterns of residents with the growth of pharmacies or other MSMEs is expressed; This being the challenge to precisely dimension other MSMEs and in other localities. At the same time, the cycles of change are getting shorter and shorter with the advancement of knowledge in the different areas. So this type of analysis should be repeated vicious cycle.

This process will not present equilibrium as long as a growth regime is maintained, that is, variations in the structural and new social behaviors that will determine opportunities or alternatives both in new, potentially successful areas, as well as in new trends in products or services. Mechanism activated by the manifest occasion of society, as well as urban planning that provokes the following action and so on. It is a fact-based tool that explains the present, allowing future decisions to be made through information.

The use of a valued macroeconomic theory (NGE) through a MSME (pharmacy) in a town (Quitilipi) in the interior of a province (Chaco) in Argentina; wielding descriptive analysis and historical information would make possible an instrument to support the development and promotion of new ventures. In addition to explaining the location of the different pharmacies. Feeding back to the system where the centripetal forces will be seen, as time passes and the evolution of the system within self-organized critical dynamism (DCAO), in an increase of the same attracting new actors to the center, making it grow to a maximum point (small investments and innovative to large shopping centers) that could be a turning point, that is, where it changes direction and transforms from streets passable by vehicles into pedestrian streets.

\section{Conclusion}

It is a specification in the application that the NGEs may have in the geographical distribution of a particular sector, as well as the possibility of extrapolating to other sectors and to other cities. The interest in knowing the explanatory elements of this geographical distribution is not recent, however, the work to be developed in this thesis focuses specifically on the study of the incidence of EGN in the location. Taken to the countryside of a small city in our province, find the intersectoral links that are established between Pharmacy companies and their urban distribution and that, on the other hand, can decisively determine a delimited area in the city; allowing to offer an analysis on alternatives of tentative urban markets for investors.

The concentration of the main businesses and other entities of importance for the development of social life emerge until causing an oversaturation, this is positive, it favors the economy, enhancing the operation of each MSME until reaching a maximum or inflection point where it arises the need for innovations, implementation of measures that exceed the existing ones and the start of the DCAO cycle. The concentration is due to public (governmental) and private decisions (MSMEs) where, for example, urban changes occur: pedestrian streets, decentralization of public institutions, promotion of new urban areas, taxes, transport, investments, multiplication of points of sale, etc.

It is worth mentioning the possibility of directing, from the urban point of view, the impulse of the urban economy, enhancing it or directing it. Likewise, the opening of a MSME depends on private economic factors, so only the feasibility is determined, not the decision. Reference is made to the set of variables that reflect the current as a direct consequence of an active past, the consequences of which will manifest themselves in the immediate future; by having positive or negative parameters that drive an economic investment decision in one direction or another.

\section{Financing details}

None.

\section{Acknowledgments}

I dedicate what I have said to each and every one of those involved in the construction of professional growth as the only means of virtue to continuous and dynamic personal improvement based on and conducive to the general common good. I want to thank my family 
first, all, for their patience, support and understanding. They are many hours stolen and a lot of time clueless or very concentrated between books, computer and sheets. Patience of my wife and my two girls together with my mother and that of my brother and his family.

\section{Conflicts of interest}

Author declares that no conflict of interest.

\section{References}

1. Castresana J. Urbanism, commerce and the city center difficult relationships. Distribución y Consumo. 1997;34:5-10.

2. Ferrer GG. Location, a strategic variable in specialized trade: an application to clothing brand trade; 2005.

3. Ruiz JMG, Martínez TL, García, IS. Problems of geomorphological evolution in abandoned fields: the jubera valley (Iberian system); 2000.

4. Albuquerque F. Local economic development in Europe and Latin America. Higher Council for Scientific Research: Madrid; 1999.

5. National Institute of Statistics and Censuses of the Argentine Republic (web).

6. Iturribarría- Pérez HE. Agglomeration economy and externalities of human capital in the metropolitan areas of Mexico. Doctoral thesis, Barcelona: Autonomous University; 2007.

7. Bósquez Remache. Feasibility study for the creation of a municipal pharmacy in the Tabacundo Parish of the Pedro Moncayo Canton; 2012.
8. Fujita M, Krugman P. The new economic geography: past, present and future. Regional Science. 2004;83:139-164.

9. Walle RE, Nieto AT. Local development, competitiveness and economic openness in Tamaulipas. Region and Society. 2014;59:113-150.

10. Fujita M. Thünen and the New Economic Geography. Regional Science and Urban Economics. 2012;42(6):907-912.

11. Duch Brown N. Location Theory; 2011.

12. Paul Krugman. Geography and commerce; 2005.

13. Fujita M, Paul K. When is the economy monocentric: von Thünen and Chamberlin unifed. Regional Science and Urban Economies. 1995;25(4):505-528.

14. Paul Krugman. Spontaneous organization of the economy. MIT Press 1997.

15. Krafta R. Urban Form, Spatial Dynamics and Self-Organized Criticality. Professor of the Department of Urbanism. Federal University of Rio Grande do Sul; 2010.

16. Paul Krugman. Development, Geography and Economic Theory. MIT Press; 1995.

17. Altamirano Marcos. History of the Chaco; 2020.

18. Fujita M, Mori T. Economics of Agglomeration. Journal of the Japanese and International Economies. 1996;10:339-378. 